\title{
EFEITO DE TRICOMAS, ALELOQUÍMICOS E NUTRIENTES NA RESISTÊNCIA DE LYCOPERSICON HIRSUTUM À TRAÇA-DO-TOMATEIRO ${ }^{1}$
}

\author{
GERMANO LEÃO DEMOLIN LEITE ${ }^{2}$, MARCELO PICANÇO ${ }^{3}$, \\ ARISTÉAALVES AZEVEDO ${ }^{4}$ e ALFREDO HENRIQUE ROCHA GONRING ${ }^{5}$
}

\begin{abstract}
RESUMO - Estudos foram conduzidos com o objetivo de verificar o efeito de tricomas, aleloquímicos e nutrientes nas folhas de partes do dossel das plantas na resistência de Lycopersicon hirsutum à traçado-tomateiro, Tuta absoluta (Lepidoptera: Gelechiidae). Foram quantificados os teores de 2-tridecanona (2-TD), 2-undecanona (2-UD), N, P, K, Ca e Mg, densidade e tipos de tricomas e tamanho das folhas nos terços apical, mediano e basal do dossel de plantas de L. hirsutum e de L. esculentum e estudaramse os efeitos destes fatores sobre características biológicas de T. absoluta. Observou-se elevação no teor de 2-TD da base para o ápice do dossel. Não se detectou diferença significativa quanto ao número de ovos de T. absoluta ao longo do dossel de L. hirsutum, constatando-se em L. esculentum maior oviposição nos terços apical e mediano do que no basal. As folhas do terço apical de L. hirsutum apresentaram maior efeito deletério sobre as larvas de traça
\end{abstract}

Termos para indexação: tomate, Lycopersicon esculentum, 2-tridecanona, 2-undecanona, nitrogênio, potássio, fósforo, cálcio, magnésio.

\section{EFFECT OF TRICHOMES, ALELLOCHEMICALS AND MINERALS ON THE RESISTANCE OF LYCOPERSICON HIRSUTUM TO TOMATO LEAF MINER}

\begin{abstract}
The objective of this work was to study the effect of trichomes, alellochemicals and minerals in the leaves of different canopy heights on the resistance of Lycopersicon hirsutum to tomato leaf miner, Tuta absoluta (Lepidoptera: Gelechiidae). Effects of 2-tridecanone (2-TD), 2-undecanone (2-UD), N, P, K, Ca and Mg levels, density and types of trichomes and leaf area on apical, medium and basal parts of plant dossel of L. hirsutum and L. esculentum on the oviposition and mines number of T. absoluta was studied. Production of 2-TD increased from the bottom to the top of the canopy. The apical part of plants of L. hirsutum showed more antibiotic effect on the caterpillar. T. absoluta oviposited more on leaves of the apical and medium portion of the plants than in the basal parts of L. esculentum.

Index terms: tomato, Lycopersicon esculentum, 2-tridecanone, 2-undecanone, nitrogen, potassium, phosphorous, calcium, magnesium.
\end{abstract}

\section{INTRODUÇÃO}

A traça-do-tomateiro Tuta absoluta (Meyrick) (Lepidoptera: Gelechiidae) é uma das pragas mais

\footnotetext{
${ }^{1}$ Aceito para publicação em 4 de fevereiro de 1999.

${ }^{2}$ Eng. Agr., M.Sc., Dep. de Biologia Animal, Universidade Federal de Viçosa (UFV), CEP 36571-000 Viçosa, MG. E-mail: gldleite@alunos.ufv.br

${ }^{3}$ Eng. Agr., D.Sc., Dep. de Biologia Animal, UFV. E-mail picanco@mail.ufv.br

${ }^{4}$ Bióloga, D.Sc., Dep. de Biologia Vegetal, UFV.

${ }^{5}$ Eng. Agr., Dep. de Biologia Animal, UFV.
}

nocivas à cultura do tomate no Brasil, sendo necessárias, para seu controle, até três aplicações semanais de inseticidas. Uma das alternativas para o combate desta praga é o uso de variedades resistentes. Para tanto, tornam-se necessárias pesquisas que possibilitem a detecção de genótipos resistentes, o conhecimento dos mecanismos de resistência envolvidos, e a execução de um programa de melhoramento (Maxwell \& Jennings, 1980; Lara, 1991).

A espécie selvagem Lycopersicon hirsutum temse mostrado promissora como fonte de resistência, devido aos aleloquímicos 2-tridecanona (2-TD) e 2-undecanona (2-UD) presentes em exsudatos pro- 
duzidos pelos tricomas glandulares das folhas (Giustolin \& Vendramim, 1994; Ventura \& Vendramim, 1996). Os mecanismos detectados são a antibiose e a antixenose. A antibiose é expressa por ação deletéria na biologia da traça, prolongando as fases larval e pupal e reduzindo a viabilidade larval, peso de pupas e fecundidade das fêmeas (Giustolin \& Vendramim, 1994), enquanto a antixenose têm se expressado por meio da menor taxa de oviposição e baixa preferência alimentar do inseto por este genótipo (Giustolin, 1991; Leite et al., 1995). De acordo com Leite et al. (1995), L. hirsutum f. glabratum (PI 134417) apresenta variação de resistência ao longo do dossel, observando-se maior oviposição de T. absoluta nas folhas do terço mediano que nos terços apical e basal do dossel.

Tem sido observado em culturas como arroz e aveia que com o aumento da concentração de $\mathrm{N}$ solúvel na seiva das plantas ocorre aumento do ataque de Sogatella furcifera e Sitobion avenae, respectivamente (Marschner, 1995). A redução do teor de K (responsável pela ativação da enzima RNA polimerase) nas folhas de arroz e citros aumenta o ataque de S. furcifera (Marschner, 1995) e das cochonilhas Lepidosaphes beckii e Saissetia oleae (Chaboussou, 1987), respectivamente, provavelmente em função da elevação da concentração de aminoácidos livres (Marschner, 1995). Em razão de o Ca ser constituinte da lamela média e parede celular (Marschner, 1995), tem-se observado que com o decréscimo do teor de Ca nas folhas de citros há aumento do ataque de L. beckii e S. oleae (Chaboussou, 1987). A maior suscetibilidade de planta a insetospraga pode estar relacionada com a expansão do limbo foliar que resulta, em geral, em decréscimo na densidade de tricomas nas folhas (Dale \& Milthorpe, 1986).

Este trabalho objetivou estudar o efeito de tricomas, aleloquímicos e nutrientes em folhas, de diferentes partes do dossel das plantas, na resistência de L. hirsutum f. glabratum (PI 134417) à traçado-tomateiro, Tuta absoluta.

\section{MATERIAL E MÉTODOS}

Esta pesquisa foi conduzida em casa de vegetação no setor de Entomologia do Departamento de Biologia Animal da Universidade Federal de Viçosa, MG, no perío- do de maio a agosto de 1996. No local foram inicialmente liberados cerca de 100 adultos de Tuta absoluta, e adicionados mais 100 adultos por semana, até o final do experimento (quatro semanas).

O delineamento experimental foi em blocos casualizados, com cinco repetições. A parcela experimental foi constituída por vaso de polietileno de cinco litros de capacidade contendo uma planta de tomateiro de três meses de idade, sendo que a terra dos vasos foi adubada com $200 \mathrm{mg}$ de $\mathrm{Ne} 100 \mathrm{mg}$ de $\mathrm{K}$ por $\mathrm{kg}$ de solo. Os fatores em estudo foram as espécies de tomateiro, Lycopersicon esculentum cv. Santa Clara (padrão de suscetibilidade) e L. hirsutum f. glabratum (PI 134417) (padrão de resistência à praga) e terços do dossel (basal - 0 a $33 \%$ da altura das plantas, mediano - 33 a $66 \%$ da altura das plantas e apical - 66 a 100\% da altura das plantas).

Foram realizadas avaliações semanais, num total de quatro, sendo utilizados como parâmetros o número de ovos de T. absoluta presentes nas faces de cada folha/parcela, e o número de minas de $T$. absoluta, que foram classificadas como pequenas (comprimento menor que $0,5 \mathrm{~cm}$ ) e grandes (comprimento maior que $0,5 \mathrm{~cm}$ ) (Picanço et al., 1995)

Para extração e quantificação dos aleloquímicos 2-tridecanona (2-TD) e 2-undecanona (2-UD), os genótipos foram coletados e pesados separadamente, na parte da manhã. Para cada genótipo coletaram-se três amostras, de $5 \mathrm{~g}$ de folhas, por tratamento. As folhas foram imersas em $50 \mathrm{~mL}$ de hexano bidestilado em recipiente de vidro ( $15 \mathrm{~cm}$ de altura por $7,5 \mathrm{~cm}$ de diâmetro), que foram fechados com tampas envolvidas por fitas adesivas para evitar evaporação destes aleloquímicos. As folhas permaneceram nestas condições por 24 horas. Após a extração, a solução hexânica foi desidratada com $\mathrm{Na}_{2} \mathrm{SO}_{4}$ anidro, e concentrada em evaporador rotativo a vácuo, a $30^{\circ} \mathrm{C}$, obtendo-se óleo. Este óleo foi redissolvido em $1 \mathrm{~mL}$ de heptano destilado, e estas amostras foram armazenadas em congelador, para análises posteriores (Silva, 1995).

As análises foram realizadas em cromatógrafo a gás, modelo CG 37, equipado com programador de temperatura, detector de ionização de chama (FID) e integrador CG 100. Foi utilizada coluna de vidro de $2 \mathrm{~m} \times 2 \mathrm{~mm}$, empacotada com OV 17 ( $1 \%$ sobre Chromosorb), detector a $260^{\circ} \mathrm{C}$ e injetor a $280^{\circ} \mathrm{C}$. O fluxo de gases, $\mathrm{H}_{2} / \mathrm{N}_{2} / \mathrm{Ar}$, foi: 30:30:300 mL minuto ${ }^{-1}$. A temperatura inicial da coluna foi de $80^{\circ} \mathrm{C}$, e esta foi mantida durante dois minutos. A temperatura foi aumentando até $150^{\circ} \mathrm{C}$, numa velocidade de $6^{\circ} \mathrm{C}$ minuto $^{-1}$.

Para estudo da densidade de tricomas, foram coletadas três folhas por tratamento. As amostras foram armazenadas em álcool 70 e diafanizadas, utilizando-se hidróxido de 
sódio a $10 \%$, por duas horas, e solução de hipoclorito de sódio comercial a $20 \%$, por 18 horas. Após a lavagem e durante a desidratação, os materiais foram corados e depois montados, entre lâmina e lamínula, utilizando-se bálsamo-do-canadá. Para coloração, as amostras permaneceram por três minutos no corante fast green (Johansen, 1940). As densidades de tricomas $/ \mathrm{mm}^{2}$ foram calculadas em folíolos diafanizados em contagens realizadas na região mediana do terceiro folíolo a partir do ápice das folhas (Channarayappa et al., 1992). Em cada amostra foram analisados 24 campos na porção mediana do limbo, região eqüidistante entre a nervura mediana e a margem. Por diferença de focalização nestes campos, foram realizadas contagens de tricomas da epiderme adaxial e abaxial. $\mathrm{Na}$ parte da manhã coletaram-se três folhas/tratamento, e avaliou-se o tamanho $\left(\mathrm{cm}^{2}\right)$ destas, utilizando-se o Sistema de Medição de Área Foliar Delta T.

Para avaliação dos teores de nutrientes nas folhas, foram retiradas três folhas ao longo do dossel de cada genótipo. Estas folhas foram acondicionadas em saco de papel kraft, os quais foram levados para estufa com circulação de ar $\left(\mathrm{a} 67^{\circ} \mathrm{C}\right)$, permanecendo aí por três dias. Após secagem, as amostras foram passadas em moinho Willey, peneira 20 malhas. As análises de N, P, K, Ca e Mg foram realizadas no Laboratório de Análise de Solo do Departamento de Fitotecnia da UFV.

O preparo da solução mineral para as determinações desses nutrientes foi realizado por digestão a seco. Do extrato obtido, o $\mathrm{K}$ foi determinado em fotômetro de chama marca Coleman, modelo 22, o Ca e Mg foram determinados em fotômetro de absorção atômica Perkin Elmer, modelo 290 B, adicionando-se cloreto de estrôncio, para se eliminar interferência de elementos minerais, principalmente P (Braga \& Defelipo, 1974); as análises de N foram realizadas utilizando-se o método de Nessler (Jackson, 1958), e o P foi determinado pelo método colorimétrico da vitamina C (Braga \& Defelipo, 1974)

Os danos de T. absoluta, tamanho das folhas, densidade de tricomas, teores de 2-TD, 2-UD, N, P, K, Ca e Mg foram submetidos a análise de variância e teste de média de Scott-Knott a 5\% de significância (Scott \& Knott, 1974). Foram realizadas análises de regressão em relação a L. hirsutum f. glabratum e L. esculentum das características do inseto e da planta, em função das densidades de tricomas e teores de 2-TD, 2-UD, N, P, K, Ca e Mg.

\section{RESULTADOS E DISCUSSÃO}

Não foram observados efeitos dos nutrientes $\mathrm{N}$, $\mathrm{P}, \mathrm{K}$ e $\mathrm{Mg}$, em ambos os genótipos, e de $\mathrm{Ca}$ em L. hirsutum f. glabratum (PI 134417) quanto ao número de ovos e minas de traça-do-tomateiro. Não foi observada diferença significativa no teor de 2-UD $(0,0015 \%$ na matéria fresca) nas folhas de L. hirsutum em função dos terços do dossel. Dimock et al. (1982) observaram um teor de 2-UD $(0,066 \%$ na matéria fresca) superior ao observado neste trabalho, talvez pelo fato de o experimento ter sido conduzido no inverno (Nichoul, 1994).

O aumento na produção de 2-TD da base para o ápice do dossel se deve ao aumento da densidade de tricomas neste mesmo sentido (Fig. 1). Como nos terços apical e mediano é onde ocorre maior ataque de T. absoluta ao tomateiro (Leite et al., 1995; Picanço et al., 1995), a elevação dos níveis destes fatores de
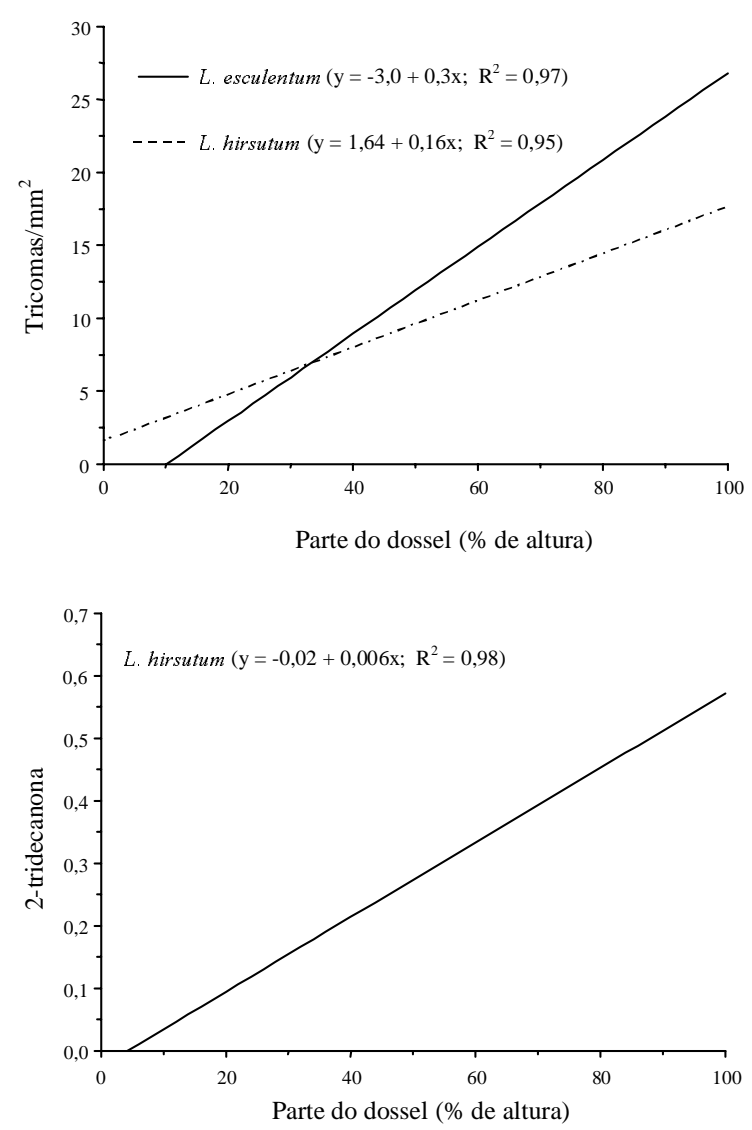

FIG. 1. Curva do teor 2-TD (\% na matéria fresca) e densidade de tricomas (média das faces $/ \mathrm{mm}^{2}$ ) em função de terço do dossel em Lycopersicon esculentum e L. hirsutum. Viçosa, MG, 1996. 
resistência nestas partes de L. hirsutum apresenta potencial de redução da suscetibilidade do tomateiro à traça. $\mathrm{O}$ teor de 2-TD observado neste experimento $(0,301 \%$ na matéria fresca) é próximo ao observado por Dimock et al. (1982) (0,369\% na matéria fresca).

Observou-se aumento da densidade de tricomas nas folhas de L. esculentum da base para o ápice, e com o aumento da área foliar diminuiu a densidade de tricomas (Dale \& Milthorpe, 1986) (Figs. 1 e 2). L. esculentum apresentou 90,31\% de tricomas tectores e L. hirsutum $97,12 \%$ de tricomas glandulares.

O maior número de ovos de traça em folhas de L. esculentum $(0,44$ e $0,62 /$ folha $)$ do que em
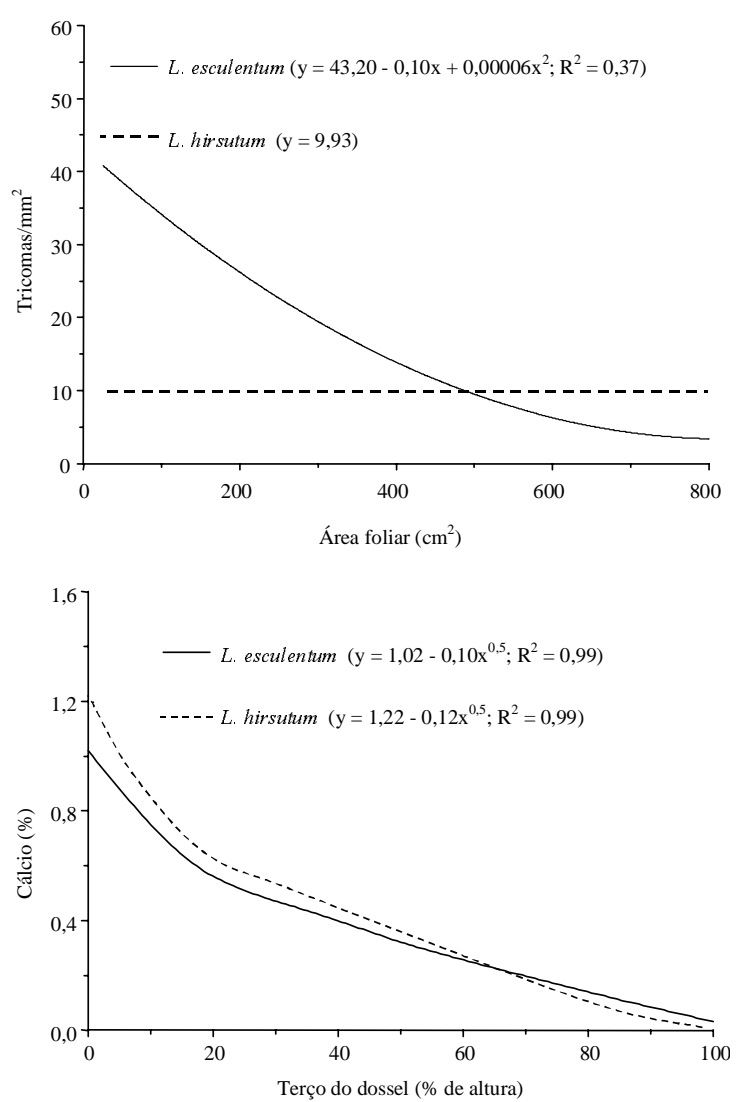

FIG. 2. Curva do teor de Ca (\% na matéria seca) em função de terço do dossel e tricomas em função de área foliar $\left(\mathrm{cm}^{2}\right)$ em Lycopersicon esculentum e L. hirsutum. Viçosa, MG, 1996.
L. hirsutum (0,02 e 0,09/folha), nos terços apical e mediano, respectivamente (Tabela 1 ), provavelmente se deve ao baixo teor de $\mathrm{Ca}$ nas folhas do terço apical e mediano de L. esculentum (Marschner, 1995), e ao elevado teor de 2-TD (Giustolin \& Vendramim, 1994; Leite et al., 1995) nas folhas de L. hirsutum nestes terços (Figs. 1, 2 e 3). Leite et al. (1995) também observaram, em teste de livre escolha em casa de vegetação, maior número de ovos de T. absoluta em folhas de L. esculentum do que nas de L. hirsutum f. glabratum (PI 134417) e L. peruvianum (LA 444-1). Não se observou diferença entre os genótipos quanto ao número de ovos de T. absoluta nas folhas do terço basal (Tabela 1), devendo-se tal fato à baixa oviposição observada devido, provavelmente, ao estado senescente das folhas.

Observou-se no terço apical maior número de minas pequenas de $T$. absoluta em folhas de L. esculentum (2,97/folha) do que nas de $L$. hirsutum $(0,19 /$ folha $)$, e nos demais terços não foi detectado diferença estatística entre os genótipos quanto a esta característica (Tabela 1). Tal fato se deve, provavelmente, à concentração de $\mathrm{Ca}$ nas folhas de L. esculentum (tecido mais tenro) e teor de 2-TD em L. hirsutum, possivelmente ocasionando maior viabilidade das larvas deste inseto nas folhas de L. esculentum do que nas de L. hirsutum, em comparação aos demais terços do dossel (Figs. 1, 2 e 3). Em teste de livre escolha, em casa de vegetação, Picanço et al. (1995) observaram maior número de minas pequenas de $T$. absoluta nas folhas de plantas de dois meses de idade dos terços mediano e basal de L. esculentum e no terço basal de plantas de L. hirsutum. Estes autores sugeriram que o menor número de minas de T. absoluta nas folhas do terço apical e mediano de L. hirsutum foi decorrente do maior teor de 2-TD nestes terços do dossel.

Observaram-se os menores números de minas pequenas e grandes em folhas do terço apical do que nos terços médio e basal de L. hirsutum (Tabela 1), provavelmente, em decorrência do maior teor de 2-TD nas folhas apicais, resultando em não-preferência da T. absoluta em ovipositar neste terço (Leite et al., 1995), além do efeito deletério de 2-TD sobre as lagartas, aumentando possivelmente a mortalidade (Giustolin \& Vendramim, 1994). 
TABELA 1. Número de ovos e de minas pequenas (comprimento menor que $0,5 \mathrm{~cm}$ ) e grandes (comprimento maior que $0,5 \mathrm{~cm}$ ) de Tuta absoluta/folha, em Lycopersicon esculentum e L. hirsutum, em função de terços do dossel. Viçosa, MG, 1996'.

\begin{tabular}{|c|c|c|c|c|c|c|}
\hline \multirow[t]{2}{*}{ Terços } & \multicolumn{2}{|c|}{ Ovos $\left(n^{\circ}\right)$} & \multicolumn{2}{|c|}{ Minas pequenas $\left(\mathrm{n}^{\circ}\right)$} & \multicolumn{2}{|c|}{ Minas grandes $\left(\mathrm{n}^{\circ}\right)$} \\
\hline & L. esculentum & L. hirsutum & L. esculentum & L. hirsutum & L. esculentum & L. hirsutum \\
\hline Apical & $0,44 \mathrm{aA}$ & $0,02 \mathrm{bA}$ & 2,97aA & $0,19 \mathrm{bB}$ & $20,06 \mathrm{aA}$ & $0,84 \mathrm{bB}$ \\
\hline Mediano & $0,62 \mathrm{aA}$ & $0,09 \mathrm{bA}$ & $1,47 \mathrm{aB}$ & $1,53 \mathrm{aA}$ & $15,74 \mathrm{aA}$ & $5,66 \mathrm{bA}$ \\
\hline Basal & $0,10 \mathrm{aB}$ & $0,00 \mathrm{aA}$ & $0,52 \mathrm{aB}$ & $1,18 \mathrm{aA}$ & $6,13 \mathrm{aB}$ & $4,66 \mathrm{aA}$ \\
\hline
\end{tabular}

${ }^{1}$ As médias seguidas pela mesma letra minúscula na linha ou maiúscula na coluna não diferem entre si, pelo teste de $\mathrm{Scott}-\mathrm{Knott}$, a $\mathrm{P}<0,05$.
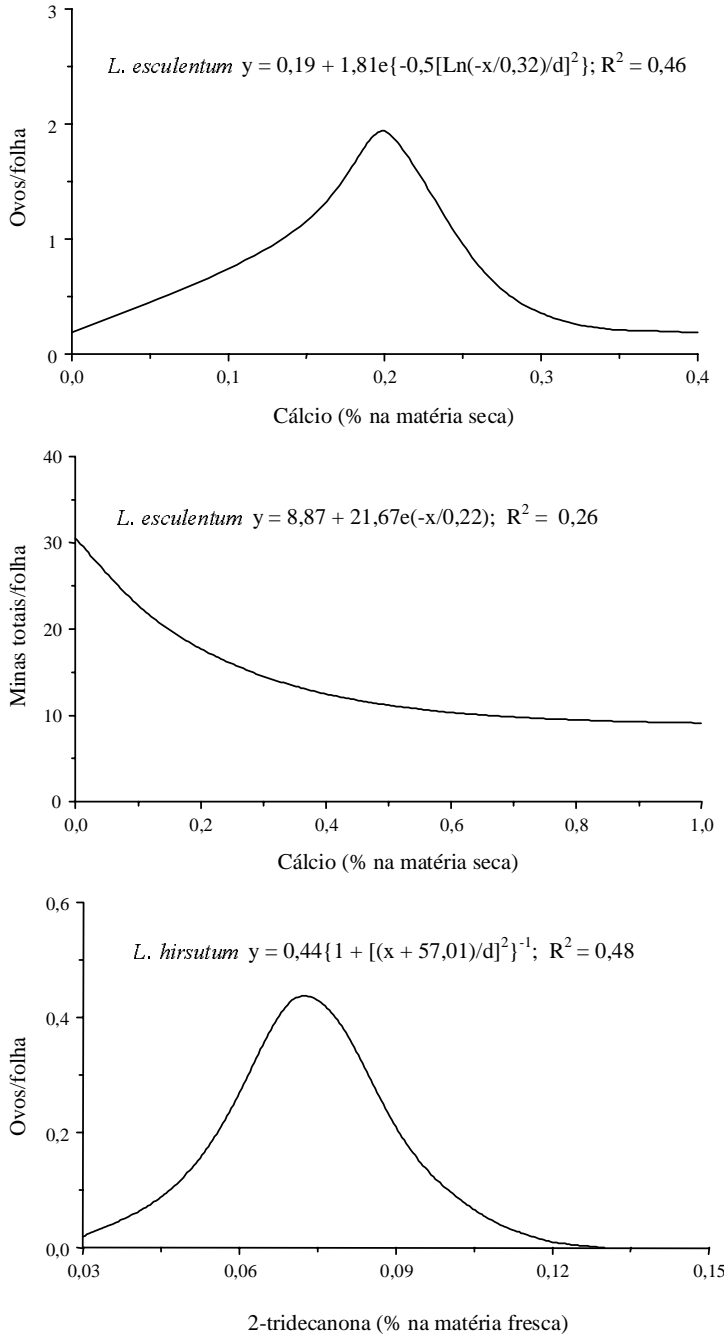

FIG. 3. Curvas de número de ovos e de minas/folha de Tuta absoluta em Lycopersicon esculentum e $L$. hirsutum em função de teores de Ca e 2-tridecanona. Viçosa, MG, 1996.
Observou-se o maior número de minas grandes de T. absoluta em folhas de L. esculentum do que L. hirsutum nos terços apical $(0,84 /$ folha $)$ e mediano $(5,66 /$ folha $)$, devido, provavelmente, à maior oviposição de T. absoluta em L. esculentum do que em L. hirsutum (Tabela 1), resultando em maior número de lagartas, além do possível efeito antibiótico de 2-TD sobre as lagartas, aumentando a mortalidade larval (Giustolin \& Vendramim, 1994).

\section{CONCLUSÕES}

1. A parte apical do dossel de Lycopersicon hirsutum é menos atacada pelas larvas de Tuta $a b$ soluta.

2. O teor de 2-TD aumenta da base para o ápice do dossel de L. hirsutum.

3. A presença dos nutrientes $\mathrm{N}, \mathrm{P}, \mathrm{K}, \mathrm{Ca}$ e $\mathrm{Mg}$ como também do aleloquímico 2-UD não afeta a resistência de L. hirsutum à T. absoluta.

\section{REFERÊNCIAS}

BRAGA, J.M.; DEFELIPO, B.V. Determinação espectofotométrica de fósforo em extratos de solos e planta. Revista Ceres, Viçosa, v.21, n.113, p.7385,1974

CHABOUSSOU, F. Plantas doentes pelo uso de agrotóxicos (a teoria da trofobiose). Porto Alegre: L \& PM, 1987. 256p.

CHANNARAYAPPA, C.; SHIVASHANKAR, G.; MUNIYAPPA, V.; FRIST, R.H. Resistance of Lycopersicon species to Bemisia tabaci, a tomato leaf curl virus vector. Canadian Journal of Botany, Ottawa, v.70, p.2184-2192, 1992.

Pesq. agropec. bras., Brasília, v.34, n.11, p.2059-2064, nov. 1999 
DALE, J.E.; MILTHORPE, D.F.L. The growth and functioning of leaves. Cambridge: Cambridge University Press, 1986. 539p.

DIMOCK, M.B.; KENNEDY, G.G.; WILLIAMS, W.G Toxicity studies of analogs of 2-tridecanone, a naturally occurring toxicant from a wild tomato. Journal of Chemical Ecology, New York, v.8, p.837-842, 1982.

GIUSTOLIN, T.A. Efeito dos aleloquímicos 2-tridecanona e 2-undecanona, presentes em Lycopersicon spp., sobre a biologia da traça-dotomateiro, Scrobipalpuloides absoluta (Meyrick, 1917) (Lep., Gelechiidae). Piracicaba: ESALQ-USP, 1991. 155p. Tese de Mestrado.

GIUSTOLIN, T.A.; VENDRAMIM, J.D. Efeito de duas espécies de tomateiro na biologia de Scrobipalpuloides absoluta (Meyrick). Anais da Sociedade Entomológica do Brasil, Londrina, v.23, n.3, p.511517, dez. 1994.

JACKSON, M.L. Soil chemical analysis. New Jersey: Prentice Hall, 1958. 498p.

JOHANSEN, D.A. Plant microtechnique. New York: McGraw Hill, 1940. p.26-203; 463-470.

LARA, F.M. Princípios de resistência de plantas a insetos. São Paulo: Ícone, 1991. 336p.

LEITE, G.L.D.; PICANÇO, M.; SILVA, D.J.H.; MATA, A.C. da; JHAM, G.N. Distribuição de oviposição de Scrobipalpuloides absoluta no dossel de Lycopersicon esculentum, L. hirsutum e $L$. peruvianum. Horticultura Brasileira, Brasília, v.13, n.1, p.47-51, 1995.
MARSCHNER, H. Mineral nutrition of higher plants. London: Academic, 1995. 889p.

MAXWELL, F.G.; JENNINGS, P.R. Breeding plants resistant to insects. New York: John Wiley, 1980 $683 p$.

NICHOUL, P. Phenology of glandular trichomes related to entrapment of Phytoseiulus persimilis A.-H. in the glasshouse tomato. Journal of Horticultural Science, Ashford Kent, v.69, p.783-789, 1994.

PICANÇO, M.C.; SILVA, D.J.H.; LEITE, G.L.D.; MATA, A.C. da; JHAM, G.N. Intensidade de ataque de Scrobipalpuloides absoluta (Meyrick, 1917) (Lepidoptera: Gelechiidae) ao dossel de três espécies de tomateiro. Pesquisa Agropecuária Brasileira, Brasília, v.30, n.4, p.429-433, 1995.

SCOTT, A.J.; KNOTT, M.A. A cluster analysis method for grouping means in the analysis of variance Biometrics, Raleigh, v.30, n.3, p.507-512, 1974.

SILVA, C.C. da. Estudo de fatores químicos de resistência a Scrobipalpuloides absoluta (Meyrick, 1917) (Lepidoptera, Gelechiidae) em três genótipos de tomateiro: Lycopersicon esculentum, Lycopersicon hirsutum, Lycopersicon peruvianum. Viçosa: UFV, 1995. 63p. Tese de Mestrado.

VENTURA, M.; VENDRAMIM, J.D. Efeito de genótipos de Lycopersicon spp. contendo diferentes teores de aleloquímicos sobre Phthorimae operculella (Zell.). Pesquisa Agropecuária Brasileira, Brasília, v.31, n.12, p. 835-842, 1996. 